\title{
Adherence to Islamic principles of success and academic achievement
}

\author{
Zuwaira Abubakar ${ }^{1}$, I. M. Maishanu ${ }^{2}$ \\ ${ }^{1}$ Department of Arabic and Islamic Studies, Sokoto State University, Nigeria \\ ${ }^{2}$ Department of Islamic Studies, Usmanu Danfodiyo University, Nigeria
}

\begin{abstract}
Article Info
Article history:

Received Jan 12, 2020

Revised Apr 7, 2020

Accepted May 1, 2020

Keywords:

Academic success

Islam

Principles

Spiritual aspect

ABSTRACT

This study was conducted in order to investigate the possible relationship between adherence to Islamic principles of success and academic performance of university students. Accordingly, a questionnaire based on Islamized principles of success (referred to as "Islamic character quotient inventory (ICQi)") was correlated with CGPA (Cumulative Grade Point Averages) of 343 students of Usmanu Danfodiyo University, Sokoto. The empirical testing indicates that the total score on ICQi correlated positively and significantly with the academic performance of the respondent. Students with either high or medium adherence to ICQi have a significantly higher CGPA than their counterparts with the low-adherence level. However, the result did not show a significant relationship between the CGPA of highly adherent individuals and that of those with medium adherence level. The findings of this research may suggest that Islamic principles are not confined to the spiritual aspect of human's life, but also relevant and useful for our mundane affairs.
\end{abstract}

This is an open access article under the CC BY-SA license.

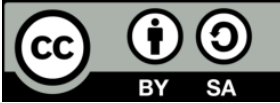

\section{Corresponding Author:}

Zuwaira Abubakar,

Department of Arabic and Islamic Studies,

Sokoto State University,

P.M.B. 2134, Birnin Kebbi Road, Near Airport, Sokoto State, Nigeria.

Email: znamadee@gmail.com

\section{INTRODUCTION}

Islam being divinely revealed religion comprises principles adherence to which ensures success not only in the afterlife but also well-being in this world. For example, several Qur'anic verses, as well as the sayings of the noble Prophet (SAW), have acknowledged that the observance of noble characters such as piety (Qur'an 3:74), justice (Qur'an 6:21) and optimism [1] is crucial for achieving any form of success. Considering the current degeneration of the Muslim community (economically, politically, morally, etc.) Islamization of various empirical disciplines such as social sciences, management sciences and education become important areas of interest in Islamic studies. One of the factors empirically associated with well-being, in terms of high socioeconomic status, is academic achievement [2]. Although various factors, such as parental engagement [3-6] and teachers factors [7, 8] have been documented to be associated with academic success, student factors, both cognitive and non-cognitive, are by far the most important [9-16]. There is a paucity of information on the level of adherence to Islamic principles among Muslim university students and its relationship to academic success. This paper, therefore, aims at assessing adherence to Islamic principles among Muslim university students in Sokoto Nigeria and its correlation to their academic performance measured as the GPA. 


\section{RESEARCH METHOD}

The sample population for this study is the two hundred level (200 level) undergraduate Muslim students of Usmanu Danfodiyo University enrolled in 2012/2013 academic session. The number of all Muslim students admitted in 2012/2013 academic session, obtained from the University unit of Managing Information System (MIS), was 6,472 out of which 3,767 were undergraduates with a male to female ratio of 3.5:1 (i.e. males 2,930, females 837). Three faculties of the university were selected through the use of computer-assisted randomization- College of Health Sciences, Faculty of Agriculture and Faculty of Sciences.

\subsection{Sample}

The required sample size was 346 . The figure was achieved after employing the RAOSOFT sample size calculator, with a 5\% margin error, $95 \%$ confidence level and 50\% response distribution. However, out of presupposition of invalid data as well as the possibility of lack of response by many respondents, 450 questionnaires were administered among the students through proportionate distribution. The response rate was [82\%]. Out of 450 questionnaires distributed to the Muslim university students, 370 questionnaires were returned. However, $15 \%$ of the returned questionnaires were excluded from the data analysis due to failure to complete at least $75 \%$ of the questions asked or due to invalid data. Thus, the total number of questionnaires used for the research analysis was 343 .

\subsection{Research instrument}

\subsubsection{Demographic characteristics}

The demographic section included information regarding age, gender, state of origin, the location of residence (Rural/Urban), country, faculty and department.

\subsubsection{Students cumulative grade point average (CGPA)}

CGPA was used as a criterion for the academic success of the students. It was gotten from students' self-report.

\subsubsection{Islamic principles of success scale}

Throughout this study, we use the term "Islamic principles of success" to refer to the basic and recommendable characters (e.g. piety (Taqwa), resoluteness $(A z m)$ ) endorsed by Islam to its adherents (Muslims) in order to help them achieve success in both the current life and the that of the hereafter. A questionnaire assessing such characters (in the name of Islamic Character Quotient inventory ICQi) was developed by the researchers. The phraseology of the questions was adopted from Islamic literature on character and some statements that suit the Islamic characters from "StrengthsFinder" and modified version of BarOn Emotional Quotient Inventory (EQi). It comprises seven (7) composite scales (characters), thirteen (13) subscales and 70 items:

a. Sense of Allah Scale: Taqwa (righteous deed for Allah's sake). Tawakkul (trust in Allah+selfdependence).

b. Islamic Perception of success: Three items assessing the respondents' opinion on what they regard as a success.

c. Interpersonal scale: Justice, Compassion and Sociability.

d. Intrapersonal scale: Izzah (self-regard), Azm (Self- actualization/Resoluteness). Uluw al-Himmah (High aspiration)

e. General Mood Scale: Qana'ah/Shukr (Contentment/Gratitude). Husn al-Zannbi-Allah (Optimism).

f. Moderation Scale: Waqar/Hilm/Tawadu (Serenity/Impulse control).

g. Adaptability: Ta'anni (Deliberateness), Flexibility and Reality testing

\subsection{Scoring of the questionnaire (ICQi)}

Each item in the questionnaire has five options: (1) very seldom or not true of me, (2) seldom true of me, (3) sometimes true of me, (4) often true of me, and (5) very often true of me or true of me. The items in the questionnaire were scored according to the Islamic general rules on character. Any statements consistent with Islamic principles were scored positively $(0,1,2,3$ and 4 for options $1,2,3,4$ and 5 respectively); while those incompatible with Islamic principles were scored negatively (4, 3, 2, 1 and 0 for options 1, 2, 3, 4 and 5 respectively).

\subsection{Data analysis}

GraphPad Prism and GraphPad Instat Statistical softwares were used to analyse the data obtained from the research instrument. Correlation coefficient and One-way ANOVA was employed in determining 
the strength of the relationship between the score on Islamic principles of success on the one hand and academic successes on the other.

\section{RESULTS AND DISCUSSION}

\subsection{Demographic characteristics of the respondents}

Table 1 which is the demographic features of the respondents showed that the number of the male respondents among students was three times more than the number of females. This is similar to the ratio of males to females (3.5:1) among the undergraduate students admitted in the 2012/2013 academic session. With regards to the locality (resident area) of the students, students from urban area doubled their pairs who came from the rural area. Ninety-six (28\%), $106(31 \%)$ and $141(41 \%)$ of the participants were students of College of health sciences (CHS), Faculty of Agriculture and Faculty of science respectively. All of them were Nigerians from 24 different states of the six geo-political zones. About 68\% (234) of the students were from seven North-Western states, 82 from five North Central States and 11 each from five North-Eastern and three South-Western states respectively. Others include 4 students from three South-Eastern states and one from a South-Southern state.

Table 2 shows a significant positive relationship between the total score of Islamic principles of success and gender of the students, indicating that females scored higher than their male counterparts. Females also gained higher scores than males in two composite characters: Sense of Allah and Islamic perception of success. However, the relationship between gender and other components of IPS: Intrapersonal, Interpersonal, General mood, Adaptability and Moderation was not significant.

Age of the students did not show any relationship with the overall score of Islamic principles of success or any of the composite scales. However, students' locality (whether rural or urban) showed significant negative relationship with Islamic principles of success and two of the composite scales, signifying that students from the urban area had higher score in IPS and two of the composite characters (general mood and Islamic perception of success) when compared with their counterparts living in rural area. However, no significant relationship was found to exist between students' area of residence (locality) and the score of other five composite characters, namely Intrapersonal, interpersonal, Moderation, Adaptability and Sense of Allah.

Table 1. Demographic characteristics of the respondents

\begin{tabular}{cccccccc}
\hline \multirow{2}{*}{ Variables } & \multicolumn{2}{c}{ Total $\mathrm{n}=343$} & \multicolumn{2}{c}{ Males Total $\mathrm{n}=262$} & \multicolumn{2}{c}{ Females Total $\mathrm{n}=81$} \\
& & Number & Percentage & Number & Percentage & Number & Percentage \\
& $15-19$ & 29 & $(8.5 \%)$ & 18 & $(6.9 \%)$ & 11 & $(13.6 \%)$ \\
\multirow{3}{*}{ Age (Years) } & $20-29$ & 310 & $(90.4 \%)$ & 241 & $(92.0 \%)$ & 69 & $(85.2 \%)$ \\
& $30-39$ & 4 & $(1.1 \%)$ & 3 & $(1.1 \%)$ & 1 & $(1.2 \%)$ \\
& Northwest & 234 & $(68.2 \%)$ & 183 & $(69.8 \%)$ & 51 & $(63.1 \%)$ \\
Geographical & Northcentral & 82 & $(23.9 \%)$ & 58 & $(22.1 \%)$ & 24 & $(29.6 \%)$ \\
Zones & Northeast & 11 & $(3.2 \%)$ & 7 & $(2.7 \%)$ & 4 & $(4.9 \%)$ \\
& Southeast & 4 & $(1.2 \%)$ & 3 & $(1.1 \%)$ & 1 & $(1.2 \%)$ \\
& South-south & 1 & $(0.3 \%)$ & 1 & $(0.5 \%)$ & 0 & $(0 \%)$ \\
Locality & Southwest & 11 & $(3.2 \%)$ & 10 & $(3.8 \%)$ & 1 & $(1.2 \%)$ \\
& Rural & 108 & $(31.5 \%)$ & 93 & $(35.5 \%)$ & 15 & $(18.5 \%)$ \\
& Urban & 235 & $(68.5 \%)$ & 169 & $(64.5 \%)$ & 66 & $(81.5 \%)$ \\
& CHS & 96 & $(28.0 \%)$ & 63 & $(24.0 \%)$ & 33 & $(40.7 \%)$ \\
& Sciences & 106 & $(30.9 \%)$ & 86 & $(32.8 \%)$ & 20 & $(24.7 \%)$ \\
& Agriculture & 141 & $(41.1 \%)$ & 113 & $(43.2 \%)$ & 28 & $(34.6 \%)$ \\
\hline
\end{tabular}

Key: CHS= College of Health Sciences.

Table 2. The relationship between demographic characteristics of the respondents and score on Islamic principles of success as well as its seven composite scales (Total number $=343$ )

\begin{tabular}{|c|c|c|c|c|c|c|c|c|}
\hline Variables & $\begin{array}{c}\text { Islamic } \\
\text { perception } \\
\text { of success }\end{array}$ & $\begin{array}{c}\text { Inter- } \\
\text { personal }\end{array}$ & $\begin{array}{l}\text { Intra- } \\
\text { personal }\end{array}$ & Adaptability & Moderation & $\begin{array}{c}\text { General } \\
\text { Mood }\end{array}$ & $\begin{array}{c}\text { Sense of } \\
\text { Allah }\end{array}$ & $\begin{array}{l}\text { Total } \\
\text { Score } \\
\text { (IPS) }\end{array}$ \\
\hline Gender $^{1}$ & $0.1715^{* *}$ & 0.07914 & 0.02642 & 0.06705 & 0.05904 & 0.09863 & $0.2053 * * *$ & $0.1665 * *$ \\
\hline Locality $^{3}$ & $-0.1257^{*}$ & -0.1107 & -0.05567 & -0.008701 & -0.06882 & $-0.2108 * * *$ & -0.05050 & $-0.1445 * *$ \\
\hline
\end{tabular}

Key: IPS= Islamic Principles of Success.

${ }^{1}$ Positive values indicate that females were more adhering than males and vice versa.

${ }^{2}$ Positive values signify that elderly respondent scored higher than younger ones.

${ }^{3}$ Negative values indicate that urban dwellers were more adhering then rural dweller and vice versa. 


\subsection{Islamic principles of success and academic achievement}

In Table 3 our statistical analysis shows a low but significant positive relationship between students' CGPA and overall score on Islamic Principles of success and five of its composite scales: General view of success, Interpersonal, Intrapersonal, Adaptability and General Mood. That is, the students who showed high compliance with IPS and the five composite characters were the one with higher academic achievement, while those with less compliance reported lower academic performance. However, no significant relationship was found between the academic performance of the students and having high/low compliance to the composite scale of moderation or sense of Allah.

One-way ANOVA analysis, in Table 4, showed that academic achievement of the respondents established a statistical relationship with all the three levels of adherence to Islamic character. Students with either high $(\geq 75 \%)$ or medium $(50-74 \%)$ level of adherence to Islamic character were found to have a significantly $(\mathrm{P}<0.01)$ higher CGPA than their counterparts with low-adherence $(<50 \%)$. Also, the average CGPA of the students with high-adherence level tends to be higher than that of their counterparts with medium-adherence level, though the difference has not reached statistical significance $(\mathrm{P}=0.05)$.

Table 3. Correlation of students' CGPA with islamic principles of success and its seven composite characters $(\mathrm{n}=343)$

\begin{tabular}{|c|c|c|c|c|c|c|c|c|}
\hline Variables & $\begin{array}{c}\text { Islamic } \\
\text { perception } \\
\text { of success }\end{array}$ & Inter-personal & Intra-personal & Adaptability & Moderation & $\begin{array}{c}\text { General } \\
\text { Mood }\end{array}$ & $\begin{array}{c}\text { Sense of } \\
\text { Allah }\end{array}$ & $\begin{array}{l}\text { Total } \\
\text { Score } \\
\text { (IPS) }\end{array}$ \\
\hline CGPA & $0.1247^{*}$ & $0.1428 *$ & $0.1338 *$ & $0.1465 *$ & 0.06924 & 0.1953 *** & 0.06463 & 0.1694 ** \\
\hline
\end{tabular}

Key: CGPA= Cumulative Grade Point Averages; Asterisk (*) represents the significance of the relationship/difference. The values with no asterisk indicate that the relationship/difference is not significant. One $*=$ significant, two $* *=$ very $^{*}$ significant, three $* * *$ or four $* * * *=$ extremely significant.

Table 4. One-way ANOVA analysis of academic success and 3 different levels of adherence to Islamic principles of success

\begin{tabular}{ccccc}
\hline COMPARISON & & & \\
Levels of Adherence to IPS (UMS) & Mean 1 \pm SE & Mean 2 \pm SE & Difference b/w the two Means & Statistical Significance \\
\hline$<50 \%$ versus $50-74 \%$ & $2.634 \pm 0.224$ & $3.383 \pm 0.052$ & 0.749 & $<0.01 * *$ \\
$<50 \%$ versus $\geq 75 \%$ & $2.634 \pm 0.224$ & $3.431 \pm 0.136$ & 0.797 & $<0.01 * *$ \\
$50-74 \%$ versus $\geq 75 \%$ & $3.383 \pm 0.052$ & $3.431 \pm 0.136$ & 0.048 & Ns \\
\hline
\end{tabular}

Key: $\angle 50 \%=$ low level of adherence, $50-74 \%=$ medium level of adherence, $\geq 75 \%=$ high level of adherence to IPS, Ns $=$ not significant, $\mathrm{SE}=$ standard error.

\section{DISCUSSION}

This study revealed a small significant positive relationship between academic achievement and Islamic principles of success. Using a related questionnaire, based on emotional inventory, several researchers have reported a similar low positive correlation between academic achievement and emotional intelligence [17-20]. However, the finding differs from that observed by Rai and Khanal [21] who documented a strong positive correlation between emotional intelligence and academic achievement. One of the composite scales, Islamic perception of success which assesses Islamic non-materialistic outlook of success, correlates positively with students' academic performance. Unlike conventional perspective on the concept of success, which relates success with the achievement of wealth [22], in Islam success is more related to mental or emotional state (e.g. peace of mind, contentment, freedom from anxiety and insecurity etc. [23]. It (Islam) attaches instrumental value to any kind of worldly material (e.g. money is worth pursuing not out of one's intrinsic love for them, but in order to use it as a means for attaining a higher position on the Day of Resurrection (Qur'an 28:77). Thus, in Islam, money is not evil but attaching intrinsic value to it is evil [24]. The result shows that students with such less materialistic outlook tend to have higher academic performance. This is in support of findings by Marvin E.Goldberg et al., who empirically found that youth with higher materialistic values orientation tend to have lower school performance [25]. A possible explanation to this result may be probably connected with the established dysfunctional behaviour of materialists, e.g. low self-actualization and vitality, depression, anxiety etc. [26], which could obstruct not only academic success but any significant pursuance.

The Islamic trait of adaptability involves thoughtfulness in taking a decision as well as applying realistic and flexible strategies in addressing issues. Our findings indicated that this Islamic character (adaptability) is an essential factor for academic achievement. Students who showed higher adherence to this character tends to have higher CGPA. This result is not surprising since such trait could help students in 
better managing new learning and cooperating with instructions, which are essential to academic achievement [27]. Also, students with higher adaptive attitude are more likely to cope with the challenging and weary condition of academic environment; hence, it could serve as a facilitator in both learning and school retention. Effective ways of coping and flexibility have previously been documented to predict academic success $[13,28]$.

The intrapersonal scale, which assessed Islamic composite character (self-regard, resoluteness and high aspiration) is found to be a predictor of high academic performance. Resoluteness (Azm) which requires action and determination is very crucial to academic performance when the stressful nature of academic learning is taken into consideration. Self-regard or self-esteem (accepting and respecting one's self) can help one to be academically successful by making one shun away from many evil behaviours (e.g. examination misconduct) which could negatively affect his academic career. This finding agrees with that of Padhy and coauthors [29].

The Islamic character of General mood embodied the feeling of contentment and optimism (for example, thinking: "Allah equips me with all I need to succeed and He is always there for my assistance; thus I will succeed"). Our results show that among all the components of Islamic principles of success evaluated general mood was the most significant predictor of academic success. The result can be explained in the sense that people with such attitude are always optimistic; they have faith that whatever Allah decreed upon them will ultimately turnout to be good either in this world, in the hereafter or both. Such a mindset energizes one's efforts and helps him withstand obstacles on the way of achieving a predetermined goal. People with this trait act positively according to the following Allah's statement:

I am as My slave thinks I am, so let him think of Me as he wishes. In another version: I am as my servant expects me. If he thinks good of Me then he will have it, and if he thinks evil of Me then he will have it $[1,23]$.

Therefore, their constant positive thinking that Allah's favour and assistance are always with them helps them to develop confidence (in all their endeavours) which is very crucial in achieving any significant achievement (like academic success).

Another finding of this research is that correlation analysis did not show a significant relationship between students' academic performance and two composite scales of the Islamic principles of success: sense of Allah and moderation. This finding suggests that sense of Allah is not a necessary condition for achieving academic success. This may explain the reason why we can get many doctors and professors from among atheists and non-believers of Islam. The finding is not contrary to Islamic teachings; instead, it is in line with the context of the following verse:

Whosoever desires (by his deeds) the reward of the Hereafter, We give him increase in his reward, and whosoever desires the reward of this world (by his deeds), We give him thereof (what is decreed for him), and he has no portion in the Hereafter (Qur'an 42:20).

Lastly, the ANOVA analysis result showed a statistically significant difference in CGPA between students with the low level of adherence to Islamic principles of success on the one hand and those with either moderate or high level of adherence on the other hand. However, no significant difference was found when the CGPA of students with moderate adherence level was compared with that of students with the high level of adherence to the principles. These findings indicate that moderate level of adherence is the required level for achieving an optimum level of academic performance, contrary to the findings of a study on marital success by Abubakar and Aboki [30] which showed that high level of adherence is necessary for attaining an optimum level of marital success.

\section{CONCLUSION}

The following conclusion can be derived from the above findings of this research: (i) Islamic principles of success, as assessed by our questionnaire, showed a small but significant correlation with academic achievement of university students. (ii) None of the composite scales of Islamic principles of success showed a negative correlation with the academic performance of the students (CGPA). Suggesting that adhering to Islamic principles is not counterproductive to worldly success, but rather is an essential factor for achieving mundane success like academic.

\section{REFERENCES}

[1] N. Al-Khattab, English Translation Of Musnad Imam Ahmad Bin Hanbal, Riyadh: Darussalam, 2012.

[2] P. Oreopoulos and K. G. Salvanes, "Priceless: The nonpecuniary benefits of schooling," Journal of Economic Perspectives, vol. 25, no. 1, pp. 159-184, 2011.

[3] H. Wang and T. Cai, "Parental involvement, adolescents' self-determined learning and academic achievement in Urban China," International Journal of Psychology, vol. 52, no. 1, pp. 58-66, 2017. 
[4] J. Karbach, et al., "Parental involvement and general cognitive ability as predictors of domain-specific academic achievement in early adolescence," Learning and Instruction, vol. 23, no. 1, pp. 43-51, 2013.

[5] K. R. Gangolu, "Adjustment and parental involvement as predictors of academic achievement of adolescents," Journal of Psychosocial Research, vol. 14, no. 1, pp. 63-72, 2019.

[6] M. Otani, "Relationships between parental involvement and adolescents' academic achievement and aspiration," International Journal of Educational Research, vol. 94, pp. 168-182, 2019.

[7] K. E. Harbour, L. L. Evanovich, C. A. Sweigart, and L. E. Hughes, "A brief review of effective teaching practices that maximize student engagement," Preventing School Failure, vol. 59, no. 1, pp. 5-13, 2015.

[8] P. Srinivasan, "Exploring the influences of teacher's intelligence and emotional intelligence on students' academic achievement," American Journal of Educational Research, vol. 3, no. 9, pp. 1159-1162, 2015.

[9] A. Muelas and E. Navarro, "Learning strategies and academic achievement," Procedia - Social and Behavioral Sciences, vol. 165, pp. 217-221, 2015.

[10] A. L. Duckworth, et al., "Cognitive and noncognitive predictors of success," Proceedings of the National Academy of Sciences of the United States of America, vol. 116, no. 47, pp. 23499-23504, 2019.

[11] M. Credé and N. R. Kuncel, "Study habits, skills, and attitudes: The third pillar supporting collegiate academic performance," Perspectives on Psychological Science, vol. 3, no. 6, pp. 425-453, 2008.

[12] M. D. Keye and A. M. Pidgeon, "Investigation of the relationship between resilience, mindfulness, and academic self-efficacy," Open Journal of Social Sciences, vol. 01, no. 06, pp. 1-4, 2013.

[13] M. K. Alimoglu, E. Gurpinar, S. Mamakli, and M. Aktekin, "Ways of coping as predictors of satisfaction with curriculum and academic success in medical school," American Journal of Physiology - Advances in Physiology Education, vol. 35, no. 1, pp. 33-38, 2011.

[14] A. Kitsantas, A. Winsler, and F. Huie, "Self-regulation and ability predictors of academic success during college: a predictive validity study," Journal of Advanced Academics, vol. 20, no. 1, pp. 42-68, 2008.

[15] S. I. Di Domenico and M. A. Fournier, "Able, ready, and willing: Examining the additive and interactive effects of intelligence, conscientiousness, And autonomous motivation on undergraduate academic performance," Learning and Individual Differences, vol. 40, pp. 156-162, 2015.

[16] K. R. Kim and E. H. Seo, "The relationship between procrastination and academic performance: A meta-analysis," Personality and Individual Differences, vol. 82, pp. 26-33, 2015.

[17] M. Yüksel, "The relationship between emotional intelligence levels and academic achievement," International Online Journal of Educational Sciences, vol. 6, no. 1, pp. 165-182, 2014.

[18] K. A. Barchard, "Does emotional intelligence assist in the prediction of academic success," Educational and Psychological Measurement, vol. 63, no. 5, pp. 840-858, 2003.

[19] M. Nasir, "Emotional intelligence as a mediator in the relationship of cultural adjustment and academic," Academic Research International, vol. 3, no. 3, pp. 275-280, 2012.

[20] J. Walsh-Portillo, "The role of emotional intelligence in college students' success," 2011.

[21] D. Rai and Y. K. Khanal, "Emotional intelligence and emotional maturity and their relationship with academic achievement of college students in Sikkim," International Journal of Education and Psychological Research (IJEPR), vol. 6, no. 2, pp. 1-5, 2017.

[22] N. Hill, The Laws of Success in 16 Lessons. Meriden, Conn.: The Ralston University Press, 1928.

[23] N. Al-Khattab, English translation of sahih muslim. Riyadh: Darussalam, 2007.

[24] M. M. Khan, The translation of the meanings of sahih Al-Bukhari, Volume 1. Riyadh: Darussalam, 1997.

[25] M. E. Goldberg, G. J. Gorn, L. A. Peracchio, and G. Bamossy, "Understanding materialism among youth," Journal of Consumer Psychology, vol. 13, no. 3, pp. 278-288, 2003.

[26] T. Kasser and A. Ahuvia, "Materialistic values and well-being in business students," European Journal of Social Psychology, vol. 32, no. 1, pp. 137-146, 2002.

[27] Y. J. Vermetten, H. G. Lodewijks, and J. D. Vermunt, "The role of personality traits and goal orientations in strategy use," Contemporary Educational Psychology, vol. 26, no. 2, pp. 149-170, 2001.

[28] C. Liang and W.-S. Lin, "The interplay of creativity, imagination, personality traits, and academic performance," Imagination, Cognition and Personality, vol. 34, no. 3, pp. 270-290, 2015.

[29] M. Padhy, S. Rana, and M. Mishra, "Self Esteem and subjective well-being: Correlates of academic achievement of students," TIJ's Research Journal of Social Science \& Management, vol. 1, no. 7, pp. 148-156, 2011.

[30] Z. Abubakar and S. A. Aboki, "Adherence to Islamic principles and marital success: examining the relevance of Islam on social life,” Islamic Quarterly, vol. 62, no. 3, pp. 407-428, 2018. 